\title{
INDICE VOL. $7 \mathrm{~N}^{\circ} 3-$ Noviembre de 1989
}

EDITORIAL

\section{INVESTIGACIÓN Y EXPERIENCIAS DIDACTICAS}

Las finalidades de la ensentanza de la Física y la Química, vistas por los profesores y alumnos franceses

Boyer, R. y Tiberghien, $A$.

La producción y la comprensión de la ciencia: la elaboración en el aprendizaje de

la ciencia escolar

Otero, $J$.

El aprendizaje del álgebra escolar desde una perspectiva psicológica

Kieran, C. y Filloy, E.

Comprensión Newtoniana de la caída de cuerpos. Un estudio de su evolución en el

Bachillerato

Acevedo Diaz, J.A.

Una aplicación de las SRTs (Scienced Reasoning Task): Análisis de la relación en-

tre el nivel cognitivo y el rendimiento escolar en $8^{\circ}$ de EGB

Saura, J.P., García de las Bayonas, A., Martínez Múñoz, F., Grupo Johann

Kepler

\section{OTROS TRABAJOS}

¿Saben los maestros la física que enseñan?

Zalamea, E. y Paris, R.

La didáctica de las ciencias en la formación inicial del profesorado: una orienta-

ción y un programa teóricamente fundamentados

Furió, C.J. y Gil, D.

Causalidad y operaciones en la interpretación de las concepciones espontáneas

Pacca, J.L.A. y Saraiva, J.A.F.

La enseñanza de los modelos sobre la naturaleza de la luz

Beléndez, A., Pascual, I. y Rosado, L.

HISTORIA Y EPISTEMOLOGÍA DE LAS CIENCIAS

La didáctica de les ciències: una empresa racional

Aliberas, J., Gutiérrez, R., Izquierdo, $M$.

\section{INFORMACIÓN BIBLIOGRÁFICA Y NOTICIAS}

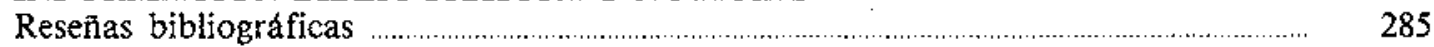

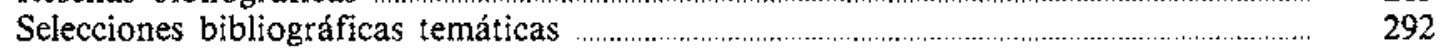

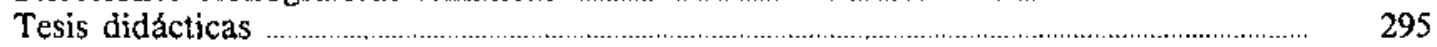

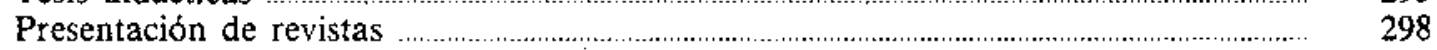

Reseñas de Congresos ………................................................................................................ 299

INTERCAMBIOS, COMENTARIOS Y CRÍTICAS

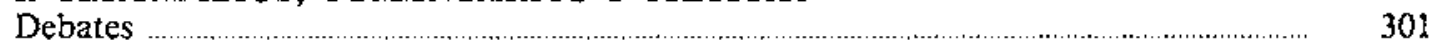

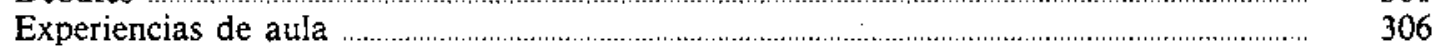

Líneas de trabajo ……………................................................................................................... $\quad 312$

Han colaborado también en este número:

Andrade, J., Caballer, M.J., Calderón, M., Castellano, A., Cunha, G., Donati, R., Favieres, A., Fernandez Navarrete, L., Figueroa, A., Garcia Clemente, F., Gonzalo, P., Laburu, C.E., Lahore, A., Lopez, V., Llorens, J.A., Martín, M., Martín, $M^{a} T .$, Manrique, Ma J., Masalles, J., Navarro, J., Omar, G., Perales, F.J., Pérez Romero, E., Silva, D., Solbes, J., Soler, J.B., Stradella, A., Tel Alberdi, L.M., Varela, P. y Vasini, E.

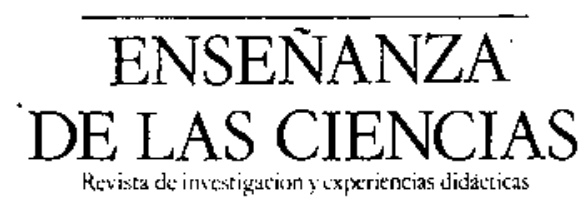

